\title{
PARTICIPAÇÃO PEDAGÓGICA NO BRINCAR DE UM GRUPO DE CRIANÇAS: O QUE REVELAM OS FAZERES DOCENTES EM CONTEXTO DE EDUCAÇÃO INFANTIL?
}

\author{
Aline SOMMERHALDER ${ }^{1}$ \\ Maria Elisa NICOLIELO ${ }^{2}$ \\ Fernando Donizete ALVES ${ }^{3}$
}

Resumo: Este artigo aborda a participação pedagógica em contexto de brincar livre no cotidiano da Educação Infantil. Focaliza modos de interação e intervenção docente nas brincadeiras infantis. Colaboraram 14 crianças com idade média de 3 anos e a respectiva professora de turma de uma escola municipal de Educação Infantil, do interior do estado de São Paulo. Utilizou-se observação participante com registro em diários de campo. Os resultados revelaram que os modos de participação pedagógica da professora transitaram entre a observação das crianças brincando, intervenções principalmente em situações de conflito e o brincar junto com elas. Nas múltiplas formas de participação pedagógica, além de fomentar interações, ações de empréstimos de brinquedos entre as crianças, cooperação, partilha, enriquecendo as possibilidades das aprendizagens infantis nas brincadeiras, houve também momentos em que esta participação docente fragilizou ou limitou as possibilidades educativas das crianças. A participação pedagógica nas brincadeiras infantis possibilita que o(a) professor(a) aproxime-se ainda mais das crianças para conhecer com mais profundidade seus interesses, necessidades, saberes e culturas. A interação docente nas brincadeiras livres é fundamental para a realização de práticas pedagógicas mais sensíveis na Educação Infantil e voltadas para as aprendizagens e o desenvolvimento humano das crianças.

Palavras-chave: Interação docente. Educação infantil. Práticas pedagógicas. Brincar. Aprendizagem e desenvolvimento humano.

\section{Introdução}

O presente artigo resulta de uma pesquisa acadêmica concluída ${ }^{4}$ e aborda modos de participação pedagógica ${ }^{5}$ em contexto de brincar livre na Educação Infantil.

\footnotetext{
${ }^{1}$ UFSCar - Universidade Federal de São Carlos - Departamento de Teorias e Práticas Pedagógicas - PósGraduação em Educação. São Carlos - SP - Brasil. 13565-905 - sommeraline@ hotmail.com

${ }^{2}$ Mestre em Educação. UFSCar - Universidade Federal de São Carlos - Pós-Graduação em Educação. São Carlos - SP - Brasil. 13565-905 - linicolielo@ hotmail.com

${ }^{3}$ UFSCar - Universidade Federal de São Carlos - Pós-Graduação em Educação. São Carlos - SP - Brasil. 13565-905 - fdalves@ufscar.br

${ }^{4}$ Pesquisa com financiamento da Capes - Coordenação de Aperfeiçoamento de Pessoal de Nível Superior - Ministério da Educação/Brasil

5 Por participação pedagógica compreendemos as múltiplas formas de envolvimento docente nas atividades ou ações propostas e/ou realizadas pelas crianças em contexto escolar.
} 
$\mathrm{Na}$ contemporaneidade, no Brasil, o brincar, concretizado pelos jogos, brinquedos e brincadeiras (SOMMERHALDER; ALVES, 2011, 2014), comumente se faz presente nas instituições de Educação Infantil. Um olhar histórico para este contexto permite anunciar que desde a criação do jardim de infância, com as influências de Froebel, o uso de jogos e brinquedos aproximou-se das práticas educativas com crianças, particularmente na Educação Infantil (KISHIMOTO, 2003). Especialmente na primeira infância e em espaços institucionalizados coletivos de educação das crianças, como a Educação Infantil, a prática lúdica é concretizada de múltiplas formas. Por exemplo, por meio do oferecimento de brinquedos para as crianças, entre uma atividade pedagógica e outra e nem sempre rotineiro; pela utilização do brincar com a intencionalidade de aquisição ou aprimoramento de competências infantis e, no dia do brinquedo, que acontece geralmente em um dia específico da semana, quando as crianças levam seus brinquedos de casa para a escola para realização de suas brincadeiras coletivas ou individuais.

No Brasil, entre os documentos orientadores de ações na Educação Infantil há o material 'Critérios para um atendimento em creches que respeite os direitos fundamentais das crianças', publicação do Ministério da Educação e Secretaria da Educação Básica. Neste documento, as autoras anunciam como um critério o direito das crianças à brincadeira, devendo ainda ser um elemento de análise e qualidade pedagógica a existência e disposição de brinquedos para as crianças na Educação Infantil (CAMPOS; ROSEMBERG, 2009).

É destaque que nas brincadeiras, as crianças expressam seus interesses, suas emoções, as compreensões que elaboram da realidade à sua volta, vivenciam e representam a realidade da forma como consideram ser mais interessante, por exemplo, encenando personagens. Mergulhadas na dimensão do imaginário, elas simbolizam e experimentam no faz-de-conta ou no 'como se', situações plurais que tiveram contato ou vivenciaram. Ao se relacionarem com seus pares, com os adultos e com os objetos lúdicos ${ }^{6}$ disponibilizados ou criados por elas, as crianças se apropriam de elementos das diversas culturas, transmitem, podem reinterpretá-los e fortalecer ainda a própria cultura lúdica infantil.

Somente a partir das culturas produzidas nas diversas esferas da sociedade é que a cultura própria do jogo e da brincadeira, ou seja, a cultura lúdica é construída e pode

\footnotetext{
${ }^{6}$ Por objeto lúdico compreende-se a partir dos estudos de Kobayashi (2009) que abrange brinquedos, jogos e livros infantis.
} 
ser reconstruída, atualizada, transformada, ampliada. Por isso, ao observar ou acompanhar crianças brincando, tem-se a oportunidade de conhecer o que faz parte de seu cotidiano, o que anunciam sobre a coragem, o conflito, o prazer, a tensão; enfim, como simbolizam suas experiências nos diversos espaços de convivência, seja com adultos, com outras crianças, em contextos coletivos ou mesmo em casa (BROUGÈRE, 1998). Brincar é assim, uma linguagem e uma prática social ${ }^{7}$ em que as crianças podem conviver com o outro humano, expressar seus saberes ${ }^{8}$ e aprender a viver a vida e a infância.

De acordo com a Resolução $n^{\circ} 5$ de 17 de dezembro de 2009 que fixa as Diretrizes Curriculares Nacionais para a Educação Infantil, brincar deve ser eixo das propostas pedagógicas e o currículo da Educação Infantil deve propor um conjunto de práticas que articulem as experiências e os conhecimentos trazidos pelas crianças com os conhecimentos sistematizados apresentados pela instituição. Nas palavras de Freire (2011), deve-se partir do 'saber de experiência feito', assumindo o momento de aprendizagem das crianças, seus interesses e necessidades. Saberes estes que revelam profundamente sobre as crianças.

Ao aproximar-se das brincadeiras e brinquedos preferidos das crianças, observar ativamente e sensivelmente, interagir e brincar com elas, o(a) professor (a) tem a possibilidade de conhecê-las de forma autêntica, conhecer suas curiosidades, escolhas, maneiras de ver e perceber o mundo e dar significados ao que acontece em seu cotidiano, conhecer seus saberes, reconhecendo as crianças da primeira infância como sujeitos competentes para aprender, mas também protagonistas para partilhar e para produzir saberes, a partir de suas próprias experiências. Com isso, ele/ela poderá realizar com maior qualidade ações pedagógicas que tenham a interlocução entre o que as crianças conhecem, pensam, compreendem, necessitam e se interessam com os conhecimentos sistematizados das múltiplas linguagens curriculares. Estas ações pedagógicas, por parte do/a professor /a da Educação Infantil, compreende um compromisso político e ético com a educação das crianças e possibilita melhor compreendê-las nas singularidades de seus contextos de vida e de seus pertencimentos

${ }^{7}$ Por prática social toma-se como referência Oliveira et al. (2014, p. 33) que consideram: “[...] as práticas sociais se constroem em relações que se estabelecem entre pessoas, pessoas e comunidades nas quais se inserem, pessoas e grupos, grupos entre si, grupos e sociedade mais ampla, num contexto histórico de nação e, notadamente em nossos dias, de relações entre nações [...].

${ }^{8}$ Compreende-se saberes a partir das ideias de Freire (2011), quando destaca o 'saber de experiência feito'. Para o autor, saberes são produzidos nas múltiplas experiências vivenciadas pelos seres humanos, saberes construídos, partilhados ao longo do convívio com o(a) outro(a) na comunidade, na escola, na família, no dia-a-dia de cada um. 
culturais, conhecimento indispensável para a promoção de uma educação mais sensível ao desenvolvimento humano. No entanto, Freire (2003) alerta que não basta apenas ouvir e conhecer, para que ocorra um processo de ensino compromissado e problematizador, é preciso partir do que as crianças trazem para ensinar-lhes o que ainda não sabem.

Com uma cobrança cada vez maior da sociedade brasileira e do próprio sistema educacional que consideram que as crianças da Educação Infantil precisam ser preparadas para o ensino fundamental, brincar ora é limitado a um dia ou outro da rotina das instituições, ora é aproveitado exclusivamente como recurso pedagógico de desenvolvimento de habilidades infantis. Com isso, há uma diminuição da oferta de espaços e tempos para brincar, especialmente do brincar livre, que proporciona de forma ampliada oportunidades para imaginar, fantasiar, representar, dar e significar as vivências da realidade, vivenciando esse brincar como parte da cultura que possibilita aprendizagens sobre a vida e jeitos de viver esta.

Esta forma de disponibilizar jogos e brincadeiras exclusivamente para a aquisição de habilidades infantis, em contextos escolares, decorre de uma compreensão reducionista sobre a função e a importância do brincar para a criança, já explicitada em literaturas científicas brasileiras e estrangeiras (BROUGÈRE, 2010; KISHIMOTO, 2003). Ao possibilitar o brincar apenas como um artifício ou uma prática de sedução (SOMMERHALDER; ALVES, 2011), utilizando o interesse das crianças por esta linguagem para que aprendam determinados conhecimentos, sustenta-se a ideia de que o brincar direcionado/dirigido é mais eficiente na promoção das aprendizagens infantis, se cotejado com o brincar livre.

Esta compreensão acaba por acentuar a oposição entre brincar educativo/pedagógico e brincar livre/recreativo. A distância assenta-se principalmente no entendimento de que a brincadeira é educativa somente quando é proposta, organizada e dirigida por um adulto, por isso a relevância dos(as) professores (as) articularem jogos e brincadeiras intencionando exclusivamente algum conhecimento ou habilidade a ser desenvolvido. De outro lado da margem permanece o brincar livre que se solidifica sobre uma imagem de liberdade para a criança e também para o(a) professor(a) da Educação Infantil, sendo promovido como prática de relaxamento e descanso, justificando a oferta entre uma atividade (trabalho pedagógico) e outra. Em sociedades capitalistas, como o Brasil, brincar livre é considerado uma atividade improdutiva, pois com ele as crianças nada produzem, não mostram resultados ou 
produtos e sendo assim, não concretizam suas aprendizagens (EMERIQUE, 2003; SOMMERHALDER; ALVES, 2011). Por isso, brincar livre está perdendo cada vez mais espaço, inclusive em contextos de Educação Infantil.

Nesse panorama da problemática, a participação pedagógica do(a) professor(a) de Educação Infantil no brincar livre se fragiliza ou inexiste, na suposição de que o planejamento e a ação do(a) docente, seja pelo acompanhamento ou pela intervenção pedagógica intencional, são desnecessários, não merecedores de preocupação ou até podem dificultar as experiências e ou aprendizagens infantis. A participação do(a) professor(a), sob diversas formas, nas brincadeiras infantis são fundamentais, entre outros aspectos, em um processo de escuta da criança (EDWARDS; GANDINI; FORMAN, 2016) e com isso, aprendizagem sobre esta criança para uma planejada e qualificada prática pedagógica. Ser parceiro(a) e partilhar da brincadeira, observar atentamente e sensivelmente a criança brincando, orientá-la, incentivá-la, sendo responsivo às necessidades infantis, planejando e organizando materiais, ambiente e cenário lúdico são ações de fomento da aprendizagem e do desenvolvimento humano.

Buscando investigar este cenário, aproximou-se de práticas pedagógicas na Educação Infantil interrogando: Há participação pedagógica do(a) professor(a) em brincadeiras livres que ocorrem na Educação Infantil? Se a participação existe, como esta ocorre? O objetivo foi conhecer e compreender a participação pedagógica em brincadeiras livres na Educação Infantil, buscando ainda apresentar algumas reflexões no que tange esse campo na formação de professores de Educação Infantil. Para tanto, considera-se que a aproximação das práticas profissionais de professores(as) é um exercício fértil para pensar o aprimoramento e/ou qualificação dos processos de formação docente.

\section{Caminho metodológico}

Foi realizada uma pesquisa de abordagem qualitativa que teve como principal característica o aprofundamento no mundo dos significados das ações e relações humanas (MINAYO, 1994). Foram participantes da investigação um grupo de 14 crianças, com idade média de 3 anos e a respectiva professora, de uma turma de uma escola pública municipal de educação infantil de uma cidade do interior de São Paulo, Brasil. A escolha pela escola deu-se em razão da mesma constituir-se em uma instituição pública municipal, localizada em um bairro central da cidade, com característica comercial, ser a mais antiga e a maior do município, no que se refere ao 
número de crianças matriculadas. Essa instituição atende crianças de bairros distintos, com pertencimento social, cultural e econômico diversos.

Acompanhou-se o cotidiano desta turma (Maternal II), especificamente o brincar livre que somente foi proposto e esteve presente na rotina das sextas-feiras, acontecendo em sala de aula e em outros ambientes da instituição que esse coletivo de crianças frequentou. Nesta instituição, às sextas-feiras foi o único dia planejado em rotina escolar para o brincar livre com brinquedos pessoais, que as crianças traziam para a escola. A escolha pela observação nas sextas-feiras deu-se justamente pelo fato deste brincar estar intencionalmente planejado para fazer parte da rotina das crianças e das práticas pedagógicas, nesse dia da semana.

O espaço de sala de aula desta turma caracteriza-se por um ambiente fresco, arejado e iluminado, com três mesas escolares infantis de seis lugares cada uma, uma mesa da professora, armários, lousa, ventilador, espelho, lixo e baú com brinquedos. Nas paredes e nos armários vários desenhos coloridos compunham o ambiente, além de cartazes, alfabeto, formas geométricas e calendário, essencialmente feitos em material de EVA (espuma sintética). Assim, a decoração da sala retratava as histórias infantis presentes nas apostilas utilizadas neste sistema municipal de ensino.

$\mathrm{Na}$ perspectiva de valorizar as vozes dos sujeitos de pesquisa e considerando a relevância das interações, do convívio e do diálogo para o desenvolvimento humano e para as aprendizagens, optou-se pela observação participante destas vivências lúdicas, com coleta de dados durante 4 meses seguidos. De acordo com Ludke e André (2012), trata-se de uma técnica de coleta de dados importante na pesquisa qualitativa, pois possibilita ao(a) pesquisador(a) um contato pessoal com a situação pesquisada, fazendo com que ele(a) experiencie diretamente essa situação e acompanhe as experiências dos sujeitos colaboradores(as) da investigação.

Estabeleceu-se um processo de convivência com as crianças e com a professora, permeado pelo diálogo, respeito e confiança. Neste sentido, Oliveira (2009) traz a expressão "convivência metodológica" para apontar a necessidade desta convivência se caracterizar como um elemento metodológico de pesquisa.

Corroborando com esta proposta e a partir do que Silva, Barbosa e Kramer (2008) apontam, entendeu-se que ao se inserir em um grupo de crianças e reconhecê-las como sujeitos e atores sociais, juntamente ao convívio foi fundamental o processo de escutar de modo sensível e ativo o que as crianças e a professora tinham para dizer, por meio de suas diversas linguagens. Esta postura não individualiza o retrato da realidade, 
pois os contextos lúdicos são marcadamente regidos por relações humanas estabelecidas entre crianças e delas com os adultos (como a professora). Ter atenção a estas interações, observar os gestos e 'ouvir' as conversas implicou considerar-se diferente delas, mas ao mesmo tempo interessado(a) e curioso(a) em conhecê-las melhor. Esta atividade de pesquisa exigiu postura humilde, com a consciência de que é fundamental aproximar-se da realidade e das relações humanas para estar junto e compreender esta prática social de brincar livre.

Foram realizados registros em diários de campo a partir das observações participantes. Esta técnica de registro se caracteriza por ser um relato escrito daquilo que o(a) pesquisador(a) viu, ouviu, acompanhou, experienciou e pensou no decorrer da pesquisa, buscando conhecer e dissecar a realidade encontrada (BOGDAN; BIKLEN, 1994). A escolha por este instrumento deu-se em razão do diário de campo constituir-se em um auxílio importante para a memória do(a) pesquisador(a), pois aspectos cruciais da pesquisa podem ser revelados a partir deste registro, permitindo um olhar aprofundado para a análise da situação pesquisada (COSTA, 2002). Ao término da pesquisa de campo foram elaborados 13 diários, um para cada inserção/dia de observação participante realizada.

A análise dos dados foi realizada qualitativamente à luz do referencial teórico escolhido. Foram respeitados todos os cuidados éticos no que se refere ao consentimento de participação, ao anonimato das participantes, por meio de nomes fictícios e à confidencialidade dos dados. Os nomes fictícios foram escolhidos pelas crianças. A investigação teve aprovação do Comitê de Ética em Pesquisa com Seres Humanos, da Universidade Pública a qual se encontrava vinculada, com parecer $\mathrm{n}$. 791.060 .

\section{Resultados e discussão}

Os resultados evidenciaram que prevaleceram momentos de participação da docente ou de presença junto às crianças em situações de brincadeiras livres. Estas participações pedagógicas ocorreram em contextos de brincadeiras livres consideradas, em sua maioria, como simbólicas. Por brincadeiras simbólicas, há os estudos de Piaget (2003) que destacam que este jogo infantil tem seu apogeu entre os dois e quatro anos de idade, sendo que é a partir dele que a criança irá satisfazer as necessidades afetivas e intelectuais tentando se aproximar dos adultos. "Sua função consiste em satisfazer o eu por meio de uma transformação do real em função dos desejos" (PIAGET, 2003, p. 28). 
Foram identificadas as seguintes brincadeiras de faz-de-conta em que ocorreram participações pedagógicas: "Brincadeira de casinha"; "Brincadeira com animais peçonhentos"; "Brincadeiras com personagens e maquiagem"; "Brincadeira com miniaturas de animais plásticos"; "Imitar os animais a partir de gestos e sons". "Brincar com carros"; "Brincar de médico"; "Brincadeiras com bonecos de super heróis, encenando personagens"; "Brincadeira de desenho livre"; "Criar castelos e bolos com areia"; "Brincadeira de cabeleireira" e "Brincadeira de imitar monstros e bruxas".

A professora realizou múltiplas formas de participação nas brincadeiras infantis. Em algumas situações, sua participação ocorreu, em primeira instância, pela observação das crianças brincando e quando necessário, pela realização de intervenções pedagógicas. Suas intervenções ocorreram, por exemplo, em momentos de conflitos entre as crianças por motivo de interesse e disputa pelos brinquedos. Este modo de participação pedagógica, quando em situações de conflitos entre as crianças, aconteceu quando as próprias crianças não conseguiram resolver estes conflitos entre elas, primeiramente.

Flor pega seu gloss na mochila e fica segurando. Ana olha ela pegar e vai até a professora.

Ana fala para a professora que estava em outra parte da sala: Eu quero passar o gloss da Flor.

Professora: Pede pra ela, pede por favor.

Ana faz expressão de choro e não pede. Chorando diz:

Ana: Não tem nada a ver, não tem nada a ver.

Professora: Nós temos que pedir, se você pedir a ela, ela te dá. É só falar pra ela deixar você passar um pouco.

Ana continua chorando e não pede.

Daiane: Vai pedir para ela. Assim ó: Me empresta um pouquinho.

Ana vai e pede.

Ana: Me empresta, por favor.

Flor empresta o gloss e Ana passa.

Professora: Isso mesmo! Está vendo como é melhor.

Professora: Vamos colocar as cadeirinhas no lugar.

As crianças ajudam e a professora agradece.

Professora: Agora vocês pegam os brinquedos para guardar porque é a hora da história.

Ana devolve o gloss para Flor e senta em seu lugar.

(Cena de Diário de Campo, n.5 - sala de aula - 29/08/14).

Neste episódio, a professora relembrou as crianças algumas regras para convívio em grupo e para interações com objetos lúdicos de uso pessoal e não coletivo. Além disso, argumentou e incentivou que as crianças conversassem e negociassem, solicitando emprestado o objeto de interesse. 
Quando frequentam a escola, as crianças têm outra concepção de posse e propriedade e é no brincar que elas se deparam com novas experiências a respeito disso. A professora, como alguém mais experiente diante dessas situações, tem o papel de estar presente e colaborar com a integração das crianças a esse novo contexto (SILVA; COSTA, 2009). No excerto do diário de campo n. 9, após a professora pedir, Daiane emprestou a maraca para Josi. Silva e Costa (2009) apontam que é importante que o(a) professor(a) fique atento as relações que estão sendo construídas pelas crianças para contribuir para que elas se deem da melhor forma.

Em outras situações de conflito entre as crianças nas brincadeiras, a participação pedagógica revelou-se mais intensa e com predomínio de ações da professora sobre as das crianças:

Gabriela começa a chorar e a professora que estava sentada em sua mesa na sala vai ver o que aconteceu.

A criança chorando diz:

Gabriela: A Ana pegou minha Peppa.

Professora: Mas você não deixa ela pegar?

Professora: Ana tem que pedir, se você tivesse pedido ela não estava chorando.

A professora pega o objeto lúdico, entrega para Gabriela e diz:

Professora: Vamos sentar na mesinha. Agora cada um pega seu brinquedo, vê se está tudo certinho e vamos sentar que lá vem história. (Cena de Diário de Campo, n. 6 - sala de aula - 05/09/14).

Nesta cena de diário de campo, como primeira participação pedagógica na brincadeira houve um questionamento realizado, especialmente dirigido para Gabriela. No entanto, a intervenção feita pela professora feita na continuidade da cena revelou uma iniciativa e tomada de decisão por parte da professora, com ênfase na ação pedagógica para a resolução do conflito, com pouca possibilidade de argumentação, negociação ou tentativas incentivadas e/ou nascidas das próprias crianças. A participação do(a) professor(a) em momentos de conflito em brincadeiras infantis é essencial, pois sua mediação contribui para que a criança aprenda a enfrentar esses conflitos (KISHIMOTO, 2010). Porém, esta participação pedagógica precisaria ocorrer de maneira mais significativa intencionando claramente a aprendizagem das crianças, para desencadear fortalecimento de interações, para incentivo de expressão e compreensão das diversas ideias infantis, de negociações e de argumentações por parte das crianças. Para isso, a professora precisaria conhecer ainda os motivos pelos quais as 
crianças se desentenderam. É fundamental que a participação pedagógica promova a participação infantil na resolução de conflitos.

Moranguinho se dirige até o canto da sala e pede para a professora para ir ao banheiro (a professora estava em pé em um canto da sala arrumando materiais). Antes de ir, deixa sua boneca em cima da mesa da professora. Ana vê a boneca ali em cima e pega para brincar, enquanto Moranguinho se ausenta da sala. Moranguinho volta e vai direto à mesa pegar sua boneca, mas como ela não a encontra começa a chorar. Fica olhando por toda a sala e quando vê que está com Ana dirige-se até ela para tirar a boneca de suas mãos. Ela puxa a boneca com força juntando-a em seu peito e abraçando-a. Ana começa a chorar e a professora diante do choro se desloca pela sala e vai até as crianças para ver o que aconteceu.

Professora: O que está acontecendo aqui? Por que você está chorando Ana?

Ana: Ela tirou a boneca de mim.

Professora: Moranguinho empresta um pouco pra ela.

Moranguinho, com expressão de choro empresta a boneca e vai à mesa em que Rebeca está brincando com as Barbies.

(Cena de Diário de Campo, n. 5 - sala de aula - 29/08/14).

$\mathrm{Na}$ relação entre a professora e as crianças, a participação pedagógica ocorreu por meio de uma intervenção docente pontual e diante de uma situação de choro infantil. No entanto, o fato da professora ter ficado afastada da cena lúdica e sem acentuada observação atenta do acontecimento, acabou por alimentar uma intervenção descontextualizada buscando resolver o choro de uma criança. Cabe destaque que as situações de conflito também trazem oportunidades para as crianças aprenderem a conviver em grupo, tomarem decisões, aprenderem a argumentar, a resolver situações e assim, exercerem e aprenderem a ser autônomas.

$\mathrm{O}$ enfretamento de contradições existentes nas relações com as pessoas proporciona aprendizagens para o fortalecimento do convívio em grupo. Ao vivenciarem situações de conflitos e tentar resolvê-los, as crianças têm oportunidades para aquisição de aprendizagens relacionadas a este convívio humano e à medida que isto se torna algo habitual, as crianças desenvolvem critérios e criam formas próprias para lidar com as diferenças de ideias e interesses. Quando a professora realiza a intervenção de maneira muito diretiva, acaba resolvendo a situação a partir de sua percepção sobre o ocorrido, podendo levar em consideração ainda somente seus valores e sua lógica (BORBA, 2005). O papel do(a) professor(a) é promover oportunidades para que as crianças vivenciem essas situações de maneira planejada e organizada, dando o 
apoio pedagógico necessário e equilibrando suas intervenções (CARVALHO; GOMES; BRUNELLO, 2009).

Coloca-se em destaque outra cena lúdica em que a criança Ben 10 negou o empréstimo do seu avião a Sidney. Com o auxílio da professora, Sidney pegou seu brinquedo e trocou com o avião de Ben 10. Diante deste episódio percebe-se que, naquele momento, Sidney não soube ou não quis argumentar ou negociar o empréstimo do brinquedo com Ben 10, chamando a professora para lhe ajudar. A professora fez uma proposta para Sidney: "Cadê seu brinquedo Sidney? Pega ele e divide com o Ben 10” e naquele momento a ação resultou na troca do objeto lúdico e ampliação da interação entre as crianças.

Ben 10: Qual avião você quer para ir no aeroporto?

Pesquisadora: Este aqui (aponto para o avião azul). Vamos decolar, "ОООНННННН".

Ben 10: Já chegamos!

Sidney se aproxima e pede os aviões para Ben 10:

Sidney: Me dá o avião?

Ben 10 demonstra não querer emprestar, balançando a cabeça negativamente, fazendo gestos negativos com o corpo e a professora que estava fora da brincadeira olha para as crianças.

Sidney olha para a professora.

Professora: Cadê seu brinquedo Sidney? Pega ele e divide com o Ben 10.

Sidney vai pegar seu brinquedo (Woody, personagem do desenho Toy Story) e eles trocam os brinquedos.

A professora fala para eles: Muito bem.

(Cena de Diário de Campo, n.3 - sala de aula-08/08/14).

Diante deste exemplo e a partir do acompanhamento de toda a cena lúdica, compreende-se que Sidney não mostrou inicialmente interesse ou não quis argumentar ou negociar o empréstimo do brinquedo com Ben 10, solicitando apoio ao olhar para a professora. A professora fez uma proposta para Sidney incentivando a troca de material entre as crianças e naquele momento este modo de participação docente foi importante como apoio para a ação da criança e incentivo a troca de brinquedos. Quando brincam juntas, as crianças precisam partilhar objetos, espaços, negociar conflitos e disputas e com isso, vão estabelecendo laços mais profundos de sociabilidade e construindo sentimentos e atitudes de solidariedade e amizade (BORBA, 2007).

A presença da professora em situações como esta é fundamental para contribuir com o desenvolvimento da autonomia e auto-organização das crianças (KISHIMOTO, 2010). Esta autora anuncia ainda que a mediação docente contribui para que a criança 
aprenda a enfrentar os conflitos durante as brincadeiras. Quando as crianças trazem seus objetos lúdicos para a escola o(a) professor(a) deve incentivá-las a dividir, a cooperar, a trocar, ajudando-as ainda a expressar e respeitar interesses e escolhas, desenvolvendo a individualidade e a identidade.

Outros modos de participação pedagógica ocorreram por meio da disponibilidade de materiais e, também em alguns momentos, por meio da brincadeira junto com as crianças. Nas cenas lúdicas a seguir, as brincadeiras foram propostas pela própria professora ou inventadas pelas crianças.

A professora juntou as mesas das crianças em sala de aula e sentou-se com elas. Durante a brincadeira, a professora fez um bolo de massinha para cantar parabéns com as crianças. Ao enfeitar o bolo, incentivou as crianças identificarem as formas geométricas quadrado e círculo e, utilizando carimbos de animais na ponta das espátulas (também disponibilizadas por ela) questionou as crianças a reconhecerem e descreverem algumas características dos animais. Ao entregar a massinha, a professora oportunizou ainda várias experiências brincantes para as crianças. A partir da imaginação e criatividade, as crianças exploraram a massinha e criaram várias cenas e objetos lúdicos.

A professora senta junto com as crianças envolta de uma mesa. Professora fala: Quem quer brincar de massinha?

Várias crianças respondem e se aproximam da professora.

Ela reune duas mesas e diz:

Professora: Quem quer brincar de massinha senta aqui (indicando a mesa em que ela está). E quem vai brincar com brinquedo senta naquela mesinha (aponta a outra mesa).

Josi, Ale, Rebeca, Ana, Flor, Gabriela e Miguel se interessam pela massinha e ficam na mesa em que a professora está. Ben 10, Sidney e Manuela sentam-se à mesa para brincar com os brinquedos.

Durante a brincadeira a professora faz um bolo.

Professora: Depois vamos cantar parabéns.

Com a massinha ela faz as formas do círculo e do quadrado e pergunta para as crianças como se chama cada uma. Depois pega a espátula que tem o desenho do cachorro e carimba na massinha e pergunta para estas crianças se aquele animal tem pena ou pelo.

Professora: Olha aqui, vou carimbar o cachorro. O que tem no corpo dele, pena ou pelo?

Apenas Josi responde.

Josi: Pelo.

E a professora responde.

Professora: Isso mesmo, o cachorro tem pelo.

A professora troca de espátula. Pega uma que tem o desenho de um pato e carimba na massinha.

Professora: E esse aqui? O pato Donald, tem pena ou pelo?

Novamente Josi responde.

Josi: Pena. 
Professora: O pato Donald tem pena.

Quando encerrou esta ação, a professora começou a cantar parabéns $e$ as outras crianças que não estavam brincando de massinha cantaram junto. Após isso, a professora deixou que as crianças brincarem com a massinha dos jeito com elas consideravam mais interessante. (Cena de Diário de Campo, n. 4 -22/08/14).

Em outra cena, a professora sentou com os meninos e começou a ver as cartas que Hulk havia trazido. As crianças Hulk, Alê e Sidney interagiram com a professora.

A professora senta com os meninos. Pega as cartas que Hulk trouxe e começa a ver. Hulk, Alê e Sidney param o que estão fazendo e começam a interagir com a professora. A professora com as cartas nas mãos pede ajuda para eles, buscando adentrar a brincadeira:

Professora: Qual personagem é esse?

Algumas crianças vão respondendo.

Ela faz isso várias vezes e depois, com a ajuda dos meninos, organiza as cartas na mesa.

Como Daiane não está brincando, a professora a chama:

Professora: Daiane vem ver as cartas.

Hulk: Tia, você sabe como faz para bater carta? (se dirigindo a professora)

Professora: É assim? (batendo com a mão sobre a carta)

Hulk: Não é assim, tia.

Professora: Então me ensina.

Mas neste momento, a professora pede para Hulk mostrar uma carta para Daiane e ele acaba não demonstrando ou explicando como fazer para a professora. (Cena de Diário de Campo, n. 6 - 05/09/14).

No brincar livre, a professora também deve incentivar que as crianças estabeleçam relações com as linguagens que estão aprendendo em outros momentos da semana. É importante que o(a) professor(a) também tenha clareza sobre as suas intencionalidades pedagógicas nos diversos modos de participação que acontecem no brincar livre. O que se destaca é que estes modos de participação pedagógica não devem fragilizar as características próprias da ação de brincar, como: liberdade, fantasia, imaginação, transformando estas experiências em atividades de repetição ou mesmo memorização e com isso, didatizando demasiadamente as práticas lúdicas.

Existem inúmeras possibilidades de incorporar a ludicidade na aprendizagem, mas para que uma atividade pedagógica seja lúdica é importante que permita a fruição, a decisão, a escolha, as descobertas, as perguntas e as soluções por parte das crianças e dos adolescentes, do contrário, será compreendida apenas como mais um exercício. (BORBA, 2007, p. 43). 
Sobre esta questão, Kishimoto (2003) aponta que a participação do(a) professor(a) nas brincadeiras das crianças não pode entrar em conflito com a ação voluntária delas, assim o papel do(a) profissional deve ser o de organizar o espaço, selecionar os brinquedos e interagir com as crianças.

A atenção dada às crianças a partir do olhar, da escuta, do diálogo, potencializa a construção da autonomia, identidade e confiança em si pelas crianças (GUIMARÃES; BARBOSA, 2009). Indo ao encontro das autoras, Freire (2003) ao discorrer sobre a relação do(a) professor(a) com as crianças, afirma que quando ele(a) dialoga com elas, as escuta, se atém as suas falas e experiências, sabe que este diálogo vai além dos conteúdos a serem ensinados, sendo válido para o desenvolvimento humano e formação para a vida.

Nesse sentido, a ideia de prática social enunciada por Oliveira et al. (2014) é colaborativa na análise destes achados da pesquisa. Como uma prática social, no brincar as crianças interagem entre elas e com os adultos e nesta convivência, experienciam trocas, partilhas, apropriações, reinterpretações, significações e com isso, aprendizagens para a vida. Toda prática social é educativa (OLIVEIRA, et al., 2014), portanto, nas brincadeiras livres as crianças se educam, em uma educação construída junto com o/a outro/a humano, em que todos podem aprender, ao mesmo tempo em que trazem suas experiências, saberes e modos de compreender a realidade e de viver em seus pertencimentos culturais.

\section{Considerações finais}

A pesquisa revelou que nesse grupo investigado, a participação pedagógica ocorreu na maioria das cenas lúdicas vividas pelas crianças. Esta participação aconteceu de diversas formas e majoritariamente em situações de conflito entre as crianças, envolvendo brinquedos. Também aconteceu por meio de intervenções diretas na cena lúdica, na observação das crianças brincando, na organização e apresentação de materiais e brincando com elas. Predominaram modos de participação pedagógica que, além de fomentar interações, constituíram-se em ações de incentivo a interações, a cooperação e a partilha entre as crianças, fortalecendo as aprendizagens infantis nas brincadeiras.

Os resultados encontrados também mostraram que esta participação aconteceu em alguns momentos de forma pontual, com prevalência de escolhas e decisões realizadas pela professora podendo, com isso, ter fragilizado ou mesmo limitado à 
participação infantil. Em momentos em que as participações envolveram observação ou acompanhamento das crianças brincando, nem sempre estes fazeres capturaram, em profundidade, o contexto da cena lúdica e com isso, ocorreram intervenções docentes descontextualizadas. Neste sentido, destaca-se o episódio entre Moranguinho e Ana, na cena de diário de campo n. 5.

Outros resultados encontrados e que merecem investigações futuras circundam, por exemplo, o intenso uso da sala de aula como espaço para brincar e com isso, a pouca exploração de outros ambientes da instituição. Em sala de aula, as mesas escolares infantis também foram acentuadamente utilizadas e serviram como apoio para que as crianças brincassem sentadas.

Sobre a prática da observação das crianças brincando, dos acontecimentos, das relações entre elas, esta ação do(a) professor(a) pode ser transformada em uma escuta sensível, um olhar atento, pois escutar não é somente com as orelhas, mas com todos os sentidos (RINALDI, 2012). A partir desta observação, o(a) professor(a) compreende como as crianças se organizam para brincar, como elas brincam, o que elas trazem para a brincadeira, compreende não apenas suas falas, mas seus gestos, olhares e expressões.

Cabe ressaltar que, em contextos de brincar livre na Educação Infantil, a participação do(a) professor(a) é fundamental para o enriquecimento do processo de aprendizagem das crianças e para o desenvolvimento humano, fomentando e mediando também ações de descobertas infantis. Com isso, modos de participação como observação da brincadeira infantil, brincar junto com as crianças possibilitam ainda o conhecimento dos contextos de vida das crianças, práticas fundamentais para compreender o universo de cada uma (FRIEDMANN, 2013).

Reforça-se a importância do(a) professor(a) estar presente nos momentos de brincar livre das crianças, envolvendo-se de forma plural em suas experiências lúdicas. No 'estar' com elas, ao brincar junto, os(as) professores(as) conhecem seus interesses e necessidades, aquilo que elas sabem, seus pertencimentos culturais, como estão se apropriando de outros elementos culturais, o que gostam e o que precisam de um apoio para compreender ou agir. Nas brincadeiras, a singularidade de cada criança se faz a mostra, pois quando se expressam mostram sua individualidade devendo ser respeitadas pelo grupo de pares e pelos adultos (KISHIMOTO, 2010).

Este conhecimento por parte dos(as) professores(as) é essencial para práticas pedagógicas mais sensíveis na Educação Infantil, comprometidas com as aprendizagens infantis e com o desenvolvimento humano. Para que os(as) professores(as) realizem 
práticas pedagógicas que oportunizem experiências significativas às crianças, é necessário compreender as particularidades de cada uma e para isso, precisam estar com elas, conhecendo suas culturas e seus diferentes saberes (SOUZA; ROSSETIFERREIRA, 2013).

Alguns achados da pesquisa, decorrentes da aproximação de uma prática profissional, para conhecimento e conhecimento da participação docente nas brincadeiras livres na Educação Infantil inspiram a reflexão sobre processos de formação de professores.

Reali, Tancredi e Mizukami (2008) apontam que entre as características da docência aprender a ensinar e a ser professor é uma delas e essas aprendizagens são processos contínuos, acontecendo ao longo da vida. Por isso, para as autoras aprender a ser professor/a não ocorre somente com a formação inicial e certamente é fundamental a oferta de processos formativos, de modo que os professores em atuação possam desenvolver-se profissionalmente.

No que tange processos de formação de professores, Barreto e Gatti (2009) retrataram uma situação preocupante em relação as matrizes curriculares das Instituições de Ensino Superior no Brasil, no que diz respeito à formação para a docência na educação infantil. A densa pesquisa destacou poucos cursos de graduação em licenciatura que promovem aprofundamento da formação nesta etapa educativa, sendo que somente $5 \%$ da carga horária dos currículos se referem a disciplinas que são ou estão relacionadas com a Educação Infantil. Sobre isso, Sommerhalder e Alves (2014) também apontaram que essa configuração dos cursos de licenciatura para atuação na educação infantil implica, portanto, diretamente na discussão sobre o lugar que o brincar vem ocupando nesta formação.

Em estudo realizado com professores em exercício, participantes de uma ação de formação lúdica, Sommerhalder e Alves (2014) mostraram fragilidades na formação inicial. Os professores revelaram um distanciamento dos cursos de formação inicial em relação aos conhecimentos sobre a cultura lúdica. Além disso, quando a temática é abordada, tanto na formação inicial quanto na continuada, predomina-se uma formação sobre o brincar, com caráter tecnicista. Estes autores $(2011 ; 2014)$ explicam que o caráter tecnicista se apresenta em processos de formação docente em que o brincar assume uma dimensão 'didatizada'. Estes processos de formação acabam por instrumentalizar os/as professores/as com um repertório de jogos e brincadeiras generalizantes que possam ser aplicados em qualquer realidade de escola, sala de aula e 
grupos de crianças, sem necessariamente incorporar uma discussão sobre para quê, para quem, quem brinca, em que contexto e qual o papel do(a) professor(a).

É a prática sem articulação com a teoria, concretizadas por atividades de vivências lúdicas, mas sem espaços para reflexão e análise destas vivências. $\mathrm{O}$ intuito de tais práticas parece ser apenas ampliar o repertório de brincadeiras e jogos do professor, para que este possa posteriormente aplicar este conjunto de atividades em sala de aula. (SOMMERHALDER; ALVES, 2014, p. 7).

A problemática nos processos de formação de professores, na temática da ludicidade também foi apontada por Emerique (2003) quando destaca que a estrutura dos cursos e programas de formação acaba por revelar e satisfazer uma demanda imaginária dos/as professores/as e, em algumas situações também dos formadores de professores. O autor destaca que, centralmente, o objetivo é promover uma instrumentalização para capacitação dos/as professores/as visando uma atuação correta, respondendo ao 'como fazer', independente do contexto, necessidades e intenções.

Ostetto (2012, p.42) também argumenta que em encontros com professores em formação, constantemente testemunha "[...] uma sensibilidade travada e o olhar embotado pelo mundo traçado em linhas retas, amparado em certezas pedagógicas" Somado a isso, desvela-se a brincadeira esquecida, o movimento contido, as cantigas silenciadas (OSTETTO, 2006). Considerando este exame realizado pela autora e o retrato apresentado pelos autores (EMERIQUE, 2003; SOMMERHALDER; ALVES, 2011, 2014; BARRETO; GATTI, 2009) algumas contradições nestes modos de participação docente podem ter como tela de fundo, processos de formação de professores fragilizados no que se refere à formação para a ludicidade. Neste sentido, podem encontrar apoio em matrizes que pouco reconhecem a aprendizagem por meio das relações humanas e as experiências de vida e saberes desse/a professor/a, adquiridos em diversas fontes sociais (TARDIF, 2002). O reconhecimento destas experiências e saberes se fazem necessários, inclusive para colocar em dúvida certas certezas que, por vezes, congelam o pensamento do/a professor/a, quando se coloca em discussão a linguagem lúdica.

Sommerhalder e Alves $(2011,2014)$ defendem processos de formação de professores que contemplem o diálogo entre teoria e prática promovendo práticas na formação docente para observação atenta e sensível da criança, além de teorização, problematização e reflexão de situações reais advindas de práticas pedagógicas envolvendo o brincar. Para tanto, sugerem que haja uma aproximação de pesquisas 
realizadas nestes contextos, casos de ensino, crônicas ou outros materiais, além da imersão em situações da própria prática profissional.

Estes autores indicam a necessidade de reconhecimento do/a profissional professor/a como um sujeito inteiro e a inclusão de estratégias para rememorar as histórias de vida na infância, em especial as lembranças e os sabores das brincadeiras. Com isso, a formação docente também deve incluir uma formação para o lúdico, com ações de vivência lúdica e reflexão teorizada destas vivências; rememoração e análise de experiências da infância, em especial das brincadeiras presentes nas experiências escolares e em outros espaços sociais, para investigação, revelação, modificações sutis de percepção ou (re)significação de crenças, ideias e concepções em torno das brincadeiras, jogos e brinquedos na educação de crianças. Cabe apontar que a análise destas representações e significados não deve ser alijada das teorias.

Essas situações devem possibilitar que o professor participe, interaja, sinta e pense sobre essas vivências a partir dos referenciais teóricos abordados no programa ou curso de formação. É um constante movimento de diálogo entre vivenciar, sentir e pensar, articulando a teoria e a prática. (SOMMERHALDER; ALVES, 2014, p.8).

É também no revisitar desta trajetória experiencial lúdica que foi vivida, da criança que habita toda pessoa professor/a, mas que foi ocultada e adormecida no profissional que talvez seja possível fincar âncoras para a mobilização de processos de formação como verdadeiras “jornadas de expansão do "ser professor"” (OSTETTO, 2014, p. 120), realizando uma formação que possa servir de alimento e alicerce para uma atuação docente na Educação Infantil que seja sensível, competente e comprometida com o desenvolvimento humano, tanto da criança quanto do próprio professor.

PEDAGOGICAL PARTICIPATION IN THE PLAY OF A GROUP OF CHILDREN: WHAT TO REVEAL THE PRACTICES TEACHERS IN THE CONTEXT OF EARLY CHILDHOOD EDUCATION? 
Abstract: This article discusses the pedagogical participation in the context of play in the early childhood education. The text shows forms of interaction and intervention in children's play. Collaborated 14 children with a mean age of 3 years and their teacher of the class in a municipal school in kindergarten, of the state of São Paulo. We used participant observation record in field diaries. The results revealed that the modes of pedagogical participation of professor transited between the observation of children playing, interventions especially in conflict situations and play with them. In many forms of participation, as interactions, actions toys loans among children, cooperation, sharing, enriching the possibilities of children's learning in play, there were also times when this participation limited educational opportunities of children. The pedagogical participation in children's play allows the teacher approaches even more children to get to know more deeply their interests, needs, knowledge and cultures.The teacher interaction at the play is essential for the achievement of pedagogical practices more sensitive in kindergarten and focused on learning and human development of children.

Key words: Teacher interaction. Early childhood education. Pedagogical practices. Play. Learning and human development.

\section{REFERÊNCIAS}

BARRETO, E. S. de S.; GATTI, B. A. Professores do Brasil: impasses e desafios. Brasília: UNESCO, 2009.

BOGDAN, R. C.; BIKLEN, S. K. O brincar como modo de ser e estar no mundo. In: BRASIL. Ensino fundamental de 9 anos: orientações para a inclusão de crianças com seis anos de idade. Brasília: MEC/SEB, 2007. p. 33-45.

BOGDAN, R. C.; BIKLEN, S. K. Notas de campo. In: BOGDAN, R. C ; BIKLEN, S. K. Investigação qualitativa em educação. Porto: Porto Editora, 1994. p.150-175.

BORBA, A. M. Culturas da infância nos espaços-tempos do brincar: um estudo com crianças de $4-6$ anos em instituição pública de educação infantil. 2005. 298 f. Tese. (Doutorado em Educação) - Universidade Federal Fluminense, Niterói, 2005.

BRASIL. Diretrizes Curriculares Nacionais para a Educação Infantil. Brasília: MEC/SEB, 2010. Disponível em

<http://portal.mec.gov.br/index.php?option=com_docman\&task=doc_download\&gid=9 769\&Itemid>. Acesso em: 24 jun. 2016.

BRASIL. Lei $n^{\circ} 11.274$, de 6 de fevereiro de 2006. Altera a redação dos art. 29, 30, 32 e 87 da Lei $n^{\circ}$ 9.394/96, que estabelece as Diretrizes da Educação Nacional, dispondo sobre a duração de 9 (nove) anos para o ensino fundamental, com matrícula obrigatória a partir de 6 (seis) anos de idade. Diário Oficial [da] União, Brasília, 07 fev. 2006. Seção 1, p.1. Disponível em: <http://www.planalto.gov.br/ccivil_03/_ato20042006/2006/lei/111274.htm>. Acesso em: 24 jun. 2016.

BRASIL. Lei ${ }^{\circ}$ 9.394, de 20 de dezembro de 1996. Estabelece as diretrizes e bases da educação nacional. lei de diretrizes e bases da educação nacional. Diário Oficial [da] União, Brasília, DF, 23 dez. 1996. Seção 1, p. 27833. Disponível em: <http://www.planalto.gov.br/ccivil_03/leis/L9394.htm>. Acesso em: 24 jun. 2016. 
BROUGÈRE, G. Brinquedo e cultura. São Paulo: Cortez, 2010.

BROUGÈRE, G. A criança e a cultura lúdica. Revista da Faculdade de Educação, São Paulo, v. 24, n.2, p. 103-116, jul./dez. 1998.

CAMPOS, M. M.; ROSEMBERG, F. Critérios para um atendimento em creche que respeite os direitos fundamentais das crianças. Brasília: MEC, 2009.

CARVALHO, R.; GOMES, S. H. P.; BRUNELLO, R. É meu, é seu, é nosso, ou é da creche? In: ROSSETI-FERREIRA, M. C. et al. (Org.). Os fazeres na educação infantil. São Paulo: Cortez, 2009. p. 67-68.

COSTA, S. A. O diário de campo como dialética intersubjetiva. In: WHITAKER, D. C. A. (Org.). Sociologia rural: questões metodológicas emergentes. Presidente Venceslau: Letras à Margem, 2002. p.151-158.

EMERIQUE, P. S. Brincaprende: dicas lúdicas para pais e professores. Campinas: Papirus, 2003.

EDWARDS, C.; GANDINI, L.; FORMAN, G. As cem linguagens da criança: a experiência de Reggio Emilia em transformação. Porto Alegre: Penso, 2016.

FREIRE, P. Pedagogia da esperança: um reencontro com a pedagogia do oprimido. São Paulo: Paz e Terra, 2011.

FREIRE, P. Professora sim, tia não: cartas a quem ousa ensinar. São Paulo: Olho d'Água, 2003.

FRIEDMANN, A. Linguagens e culturas infantis. São Paulo: Cortez, 2013.

GUIMARÃES, D. ; BARBOSA, S. Cadê a Viviane? Cadê a Ingrid? visibilidade e invisibilidade das crianças na creche. In: KRAMER, S. (Org.). Retratos de um desafio: crianças e adultos na educação infantil. São Paulo: Ática, 2009. p.35-46.

KISHIMOTO, T. M. Brinquedos e brincadeiras na educação infantil. In: SEMINÁRIO NACIONAL: CURRÍCULO EM MOVIMENTO: PERSPECTIVAS ATUAIS, 1., 2010, Belo Horizonte. Anais... Belo Horizonte: [MEC], 2010. p.01-20.

KISHIMOTO, T. M. Froebel e a concepção de jogo infantil. In: KISHIMOTO, T. M. (Org.). O brincar e suas teorias. São Paulo: Cengage Learning, 2003. p.57-78.

KOBAYASHI, M. C. M. Classificação dos objetos lúdicos. Revista Direcional Educador, [S.1.], Ano 5, n. 50, p. 12-15, 2009.

LUDKE, M.; ANDRÉ, M. E. D. A. Pesquisa em educação: abordagens qualitativas. São Paulo: E.P.U, 2012.

MINAYO, M. C. de S. Ciência, técnica e arte: o desafio da pesquisa social. In: MINAYO, M. C. de S. (Org.) Pesquisa social: teoria, método e criatividade. Petrópolis: Vozes, 1994. p.9-29. 
OLIVEIRA, M. W. et al. Processos educativos em práticas sociais: reflexões teóricas e metodológicas sobre pesquisa educacional em espaços sociais. In: OLIVEIRA, M. W.; SOUSA, F. R. (Org.). Processos educativos em práticas sociais: pesquisa em educação. São Carlos: EduFSCar, 2014. p.29-46.

OLIVEIRA, M. W. et al. Pesquisa e trabalho profissional como espaços e processos de humanização e de comunhão criadora. Caderno CEDES, Campinas, v. 29, n.79, p. 1-7, 2009.

OSTETTO, L. E. Danças circulares na formação de professores: a inteireza de ser na roda. Florianópolis: Letras Contemporâneas, 2014.

OSTETTO, L. E. Arte e educação, crianças e adultos: diálogos para transver o mundo. In: CONGRESSO INTERNACIONAL DE EDUCAÇÃO FÍSICA, ESPORTE E LAZER, 2.; COLÓQUIO DE PESQUISA QUALITATTIVA EM MOTRICIDADE HUMANA, 5.; SHOTOWORKSHOP, 6., 2012, São Carlos. Anais... São Carlos: [EdUFSCAR], 2012. p.41-49.

OSTETTO, L. E. A arte no itinerário da formação de professores: acender coisas por dentro. Reflexão e Ação, Santa Cruz do Sul, v. 14, n. 1, p. 29-43, 2006.

PIAGET, J. Seis estudos de psicologia. Rio de Janeiro: Forense Universitária, 2003.

REALI, A. M. M. R.; TANCREDI, R. M. S. P.; MIZUKAMI, M. G. N. Programa de mentoria on line: espaço para o desenvolvimento profissional de professoras iniciantes e experientes. Educação e Pesquisa, São Paulo, v. 34, n.1, p. 77-95, 2008.

RINALDI, C. Documentação e avaliação: como se relacionam?. In: RINALDI, C. Diálogos com Reggio Emilia: escutar, investigar e aprender. São Paulo: Paz e Terra, 2012. p.117-138.

SILVA, A. H. A.; COSTA, E. F. O adulto, um parceiro especial. In: ROSSETIFERREIRA, M. C.; MELLO, A. M.; T. VITORIA, T.; CHAGURI, A. C. (Org.). Os fazeres na educação infantil. São Paulo: Cortez, 2009. p.49-50.

SILVA, J. P.; BARBOSA, S. N. F.; KRAMER, S. Questões teórico-metodológicas da pesquisa com crianças. In: CRUZ, S.H.V. (org.). A criança fala: a escuta de crianças em pesquisas. São Paulo: Cortez, 2008. p. 79-101.

SOMMERHALDER, A.; ALVES, F. D. Formação lúdica de professoras: a voz das participantes em uma atividade de extensão universitária a distância. Quaestio, Sorocaba, v.16, n.1, p. 105-121, 2014.

SOMMERHALDER, A.; ALVES, F. D. Jogo e a educação da infância: muito prazer em aprender. Curitiba: CRV, 2011.

SOUZA, T. N.; ROSSETI-FERREIRA, M. C. Uma infância melhor. Revista Educação: Cultura e Sociologia da Infância, [S.1.], v. único, p. 123-135, 2013.

TARDIF, M. Saberes docentes e formação profissional. Petrópolis: Vozes, 2002. 